EESTI NSV TEADUSTE AKADEEMIA TOIMETISED. VIII KÖIDE BIOLOOGILINE SEERIA. 1959, NR. 4

ИЗВЕСТИЯ АКАДЕМИИ НАУК ЭСТОНСКОЙ ССР. ТОМ VIII СЕРИЯ БИОЛОГИЧЕСКАЯ, 1959, № 4

\title{
TURBATUHA KEEMILINE KOOSTIS JA TEMAS SISALDUVATE TOITEELEMENTIDE OMASTATAVUS TAIMEDE POOLT
}

\author{
H. KÄRBLANE, \\ pōllumajandusteaduste kandidaat
}

Eestis on turvas tähtsaks kohalikuks kütuseks. Tema põlemisel jääb järele rohkesti tuhka. Arvestades turba keskmiseks tuhasuseks $6 \%$, peavad vabariigi elektrijaamad ja muud turvaskütusel töötavad ettevōtted aasta jooksul välja vedama enam kui 33000 t turbatuhka. Vaatamata sellele kasvab turvaskütuse osatähtsus järjest, mille tagajärjel suureneb ka tuha hulk. Nii on mõnede elektrijaamade ja tehaste juurde tuhamägedena kuhjunud suured turbatuha tagavarad (Ellamaa elektrijaamas, Järvakandi tehastes, Ulila elektrijaamas jm.). Selline kogunev turbatuhk on tööstuses ja elektrijaamades ballastiks, millest lahtisaamine on seotud sageli suurte kuludega.

Et välja selgitada turbatuha rahvamajanduslikku tähtsust ja kasutamise võimalusi, selleks määrati tema keemiline koostis ja uuriti temas sisalduvate tähtsamate toiteelementide omastatavust taimede poolt.

Tabelis 1 ongi toodud eri päritoluga turbatuhkade keemiline koostis.

Tabel 1

Turbatuha keemiline koostis

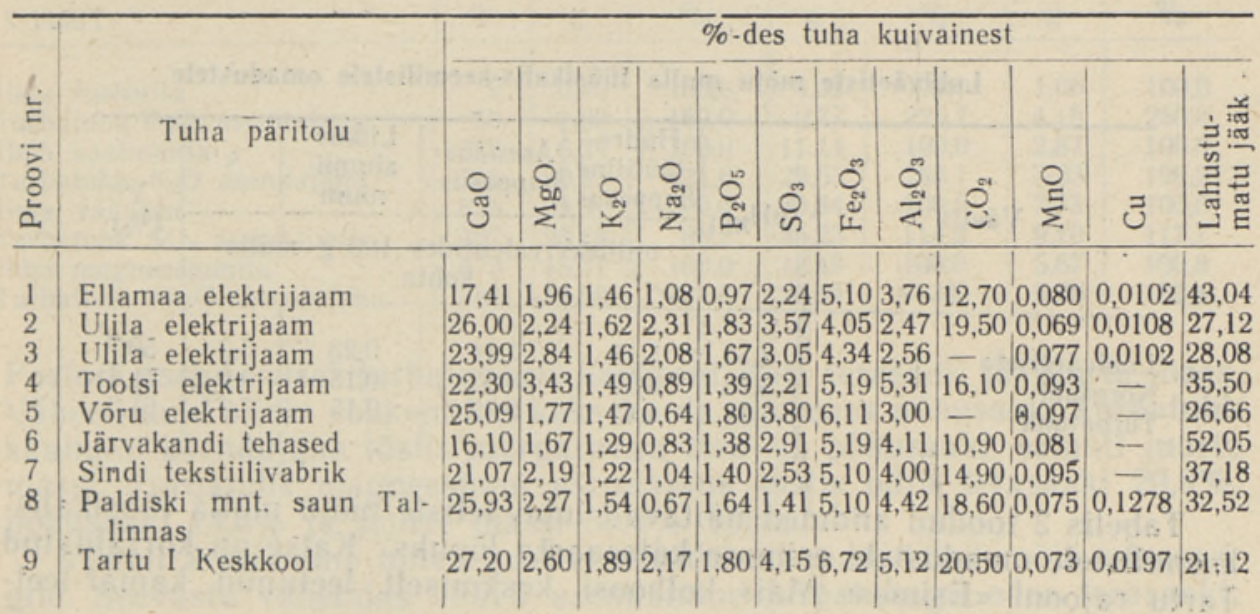


Erinevused turbatuha keemilises koostises on tingitud ühelt poolt sellest, et kütteks kasutatav turvas pärines eri kohtadest, ja teiselt poolt sellest, et mõnel pool kasutati teda segus kivisöega (proov nr. 6). Kivisöetuhk (räbu) alandab järelejäävas tuhasegus $\mathrm{CaO}, \mathrm{MgO}, \mathrm{K}_{2} \mathrm{O}, \mathrm{P}_{2} \mathrm{O}_{5}$ ja mõnede teiste elementide sisaldust, kusjuures suureneb soolhappes lahustumatu jäägi hulk.

Suurt soolhappes lahustumatut jääki ning väiksemat lubja-, kaaliumi-, fosfori-, väävli- ja süsinikusisaldust näeme ka Ellamaa elektrijaamast võetud tuhaproovis (proov nr. 1). See turvas on ebakvaliteetselt üles töötatud, mistōttu liivasisaldus temas on kõrge. Turba hulka segunenud liiva tōttu tõuseb kütuse tuhasus sageli $30 \%$-ni ja isegi üle selle. Ka järelejääv tuhk on liivarikas, mis pōhjustabki ta erinevat keemilist koostist.

Turba põletamisel harilikes ahjudes (proov nr. 9) kasutatakse tule alustamiseks kergemini süttivat puitu. Kaltsiumi-, kaaliumi-, fosfori- ja väävlirikkam puutuhk, segunedes koldes turbatuhaga, tõstab mainitud elementide sisaldust järelejäävas tuhasegus.

Ulila elektrijaama tuhaproovidest on proov nr. 2 võetud otse jõujaama tuhahunnikust. Proov nr. 3 pärineb Raadi õppe- ja katsemajandisse transporditud ja seal suve läbi pōllul seisnud väikesest hunnikust (5 ts). Mõlema proovi võrdlemisel näeme nende keemilises koostises erinevust. Lahtise taeva all väikeses hunnikus seistes on vähenenud suhteliselt kaaliumi-, kaltsiumi-, fosfori- ja väävlisisaldus, kuna raua- ja magneesiumiprotsent on tõusnud.

Eespool toodust selgub, et turbatuhk sisaldab rohkesti taimedele vajalikke toiteelemente. Et need saaksid kasutatavaks, peavad nad olema taimede poolt omastatavad. Sellelt seisukohalt on tähtis, millise keemilise ühendina üks või teine element turbatuhas esineb, sest sellest oleneb antud elemendi lahustuvus vees vōi nōrkades hapetes. Küllaltki rohke karbonaatide $\left(\mathrm{CO}_{2}^{-}\right)$sisaldus analüüsitud proovides lubab oletada, et suur osa turbatuha kaltsiumist esineb karbonaatidena.

Turbatuhas sisalduva kaltsiumi suhteliselt head lahustuvust ja kiiret reageerimist mullaga tõestavad ka 1955. a: suvel läbiviidud põldkatsed. Vaatamata sellele, et lubiväetised olid külvatud kevadel enne kultivaatoriga harimist ja et suvi oli sademetevaene, reageerisid mullaga kiiresti nii turbatuhk kui ka võrdluseks võetud nõrglubi, milles kaltsium esineb karbonaadina, ja parandasid tunduvalt mulla füüsikalis-keemilisi omadusi juba esimese vegetatsiooniperioodi lõpuks.

Tabel 2

Lubiväetiste mõju mulla füüsikalis-keemilistele omadustele

\begin{tabular}{|c|c|c|c|c|c|c|}
\hline \multirow{2}{*}{$V$ äetis } & \multirow{2}{*}{$\mathrm{pH}_{\mathbf{K C l}}$} & \begin{tabular}{|c|} 
Hüdro- \\
lüütiline \\
happesus
\end{tabular} & $\begin{array}{l}\text { Asendus- } \\
\text { happesus }\end{array}$ & $\begin{array}{l}\text { Liikuv } \\
\text { alumi- } \\
\text { nium }\end{array}$ & $\mathrm{S}$ & \multirow{2}{*}{$\begin{array}{c}V \\
(\%)\end{array}$} \\
\hline & & \multicolumn{4}{|c|}{$\begin{array}{c}\text { milliekvivalentides } 100 \mathrm{~g} \text { mulla } \\
\text { kohta }\end{array}$} & \\
\hline $\begin{array}{l}\text { Lubiväetiseta } \\
\text { Nörglubi } \\
\text { Turbatuhk }\end{array}$ & $\begin{array}{l}4,54 \\
5,76 \\
6,38\end{array}$ & $\begin{array}{l}5,15 \\
3,57 \\
4,45\end{array}$ & $\begin{array}{l}0,44 \\
0,33 \\
0,33\end{array}$ & $\begin{array}{r}0,23 \\
0,18 \\
0,15\end{array}$ & $\begin{array}{l}5,3 \\
9,0 \\
7,2\end{array}$ & $\begin{array}{l}50,7 \\
71,6 \\
61,9\end{array}$ \\
\hline
\end{tabular}

Tabelis 2 toodud andmed näitavad lubiväetiste mõju mulla füüsikalis: keemilistele omadustele esimese katseaasta lōpuks. Katse on korraldatud Tartu rajooni «Esimese Mai» kolhoosi keskmiselt leetunud kamar-leetmullal. 
Kumbagi lubiväetist anti 5 t/ha. Et külvatud turbatuha niiskussisaldus oli $21 \%$ ja leelisus $\left(\mathrm{CaCO}_{3}\right) 53,5 \%$, nõrglubjal vastavalt 18 ja $87,5 \%$, anti hektarile turbatuhaga umbes 2,1 tonni ja nõrglubjaga 3,6 tonni $\mathrm{CaCO}_{3}$. Sellega seletubki nōrglubja tugevam toime mulla füüsikaliskeemilistele omadustele.

Uhe või teise elemendi omastatavust näitab ka tema lahustuvus vees või nõrkades hapetes.

Vees lahustuvad ühendid on taimede poolt otseselt omastatavad. Vees lahustumatud mineraalühendid seevastu peab taim oma juurtest erituvate orgaaniliste hapete toimel mutma endale kättesaadavaks. Katseliselt on kindlaks tehtud, et $2 \%$-lises sidrunhappeleotises lahustuvad ühendid on taimede poolt omastatavad.

Analüüside tulemused näitavad, et turbatuhas sisaldub keskmiselt $0,5 \%$ vees ja $0,76 \% 2 \%$-lises sidrunhappes lahustuvat kaaliumi $\left(\mathrm{K}_{2} \mathrm{O}\right)$. Seega moodustab vees lahustuv $\mathrm{K}_{2} \mathrm{O}$ ühe kolmandiku ja sidrunhappes lahustuv $\mathrm{K}_{2} \mathrm{O}$ üle poole turbatuha üldkaaliumist. Vees lahustuvat fosforit $\left(\mathrm{P}_{2} \mathrm{O}_{5}\right)$ leidub turbatuhas $0,28 \%$ ja $2 \%$-lises sidrunhappes lahustuvat $\mathrm{P}_{2} \mathrm{O}_{5}$ on $0,87 \%$ (s. o. keskmiselt pool turbatuha $\mathrm{P}_{2} \mathrm{O}_{5}$ kogusest).

Et selgusele jõuda turbatuhas sisalduvate toiteelementide omastatavuses taimede poolt, selleks korraldati rida nõukatseid kvartsliival ja mitmesugustel muldadel.

Toitaineid mittesisaldaval kvartsliival läbiviidud katsetes anti kasvuks vajalikud toiteelemendid taimedele Prjanišnikovi toiteseguna.

Turbatuhas sisalduva fosfori, kaaliumi, väävli ja magneesiumi omastatavuse uurimiseks taimede poolt korraldati vastavad katseseeriad odraga, iga seeria kahes variandis. Esimeses katseseerias jäeti Prjanišnikovi toitesegust välja uuritav element, teises katseseerias asendati see turbatuhaga.

Katsetest selgus, et fosfori, kaaliumi ja magneesiumi ärajätmine toitesegust vähendas tublisti odrasaaki. Toitesegust ärajäetud elementide asendamine turbatuhaga soodustas aga taimede kasvu (tab. 3).

Tabel 3

Turbatuha mõju odrasaagile

\begin{tabular}{|c|c|c|c|c|c|c|c|}
\hline \multirow{3}{*}{ Katsevariant } & \multicolumn{3}{|c|}{ Teri } & \multicolumn{2}{|c|}{ Põhku } & \multicolumn{2}{|c|}{ Juuri } \\
\hline & \multicolumn{7}{|c|}{ keskmiselt nõu kohta } \\
\hline & tk. & g & $\%$ & a & $\%$ & g & $\%$ \\
\hline Ilma fosforita & $y$ & 0,10 & 100,0 & 4,31 & 100,0 & 1,66 & 100,0 \\
\hline Turbatuhk $\mathrm{P}_{2} \mathrm{O}_{5}$ asendajana & 66 & 1.69 & 169,0 & 9,77 & 226,7 & 4,15 & 250,0 \\
\hline Ilma kaaliumita & 322 & 6,29 & 100,0 & 11,14 & 100,0 & 2,87 & 100,0 \\
\hline Turbatuhk $\mathrm{K}_{2} \mathrm{O}$ asendajana & 728 & 20,23 & 321,6 & 29,53 & 265,1 & 5,63 & 196,2 \\
\hline Ilma väävlita & 875 & 32.51 & 100,0 & 30,84 & 100,0 & 7,73 & 100,0 \\
\hline Turbatuhk $\mathrm{SO}_{3}$ asendajana & 797 & 28,18 & 86.7 & 35,23 & 114,2 & 9,10 & 117,7 \\
\hline Ilma magneesiumita & 473 & 15,71 & 100,0 & $18,4,3$ & 100,0 & 5,67 & 100,0 \\
\hline $\mathrm{MgO}$ asendajana & & 18.98 & 120,8 & 20,94 & 113,6 & 8.70 & 153,4 \\
\hline
\end{tabular}

Fosfori asendamisel turbatuhaga kasvasid eriti terasaak ja juurte mass. Vähem, kuid siiski rohkem kui kaks korda suurenes põhusaak. Turbatuhk kaaliumi asendajana tõstis märgatavalt tera- ja põhusaaki, samuti juurte massi. Turbatuhk magneesiumi asendajana tôstis odra terasaaki $20,8 \%$, põhusaaki $13,6 \%$ ja juurte massi $53,4 \%$ võrra.

Väävli ärajätmine toitesegust ei avaldanud pidurdavat mõju odrasaagile. Seevastu vähendas väävli asendamine turbatuhaga odra terasaaki; küll aga kasvasid põhusaak ja juurte mass. 
Turbatuhas sisalduvate toiteelementide omastatavust taimede poolt näitab ka viienäda!aste odrataimede kasv fotodel $1-4$.

Eespool kirjeldatud katsetele analoogilisi korraldati ka hernega. Siin ilmnes turbatuha positiivne toime taime kasvusse veelgi selgemalt. Hernele kui liblikõielisele osutus tähtsaks toiteelemendiks ka väävel. Selle ärajätmine toitesegust pidurdas taimede kasvu tublisti: juurestik oli nōrk ja teri peaaegu ei moodustunud. Väävli asendamisel turbatuhaga muutus taimede kasv jälle normaalseks ja terasaak suurenes enam kui 38 korda. Neid fakte kinnitab ka viienädalaste hernetaimede kasv, mida näitab foto 5 .

Nagu meie katsetest selgub, sisaldab turbatuhk peale lämmastiku kõiki taimedele vajalikke toiteelemente, mis ühtlasi on taimede poolt omastatavad. Sellest järeldub, et senini väärtusetuks ballastiks peetud turbatuhka võib edukalt kasutada nii põllul kui ka aias.

Turbatuha soodustavat mõju taimede kasvule uurisime ka nõu- ja pōldkatsetes

Pärnu-Jaagupi rajooni Kirovi-nimelisest kolhoosist võetud tüüpilisel kamar-karbonaatmullal $\left(\mathrm{pH}_{\mathrm{KCl}}=6,60\right.$; liikuvat $\mathrm{P}_{2} \mathrm{O}_{5}$ on $5,8 \mathrm{mg}$ ja liikuvat $\mathrm{K}_{2} \mathrm{O}$ on $25,0 \mathrm{mg} 100 \mathrm{~g}$ mulla kohta) lämmastiku foonil korraldatud nõukatses suurenes turbatuha lisamisel suhkrupeedi juurikate ja pealsete saak enam kui poolteist korda (tab. 4, foto 6).

Turbatuha mõju suhkrupeedisaagile

Tabel 4

\begin{tabular}{l|c|c|c|c}
\hline \multirow{2}{*}{ Katsevariant } & \multicolumn{2}{|c|}{ Toorpeeti } & \multicolumn{2}{c}{ Lehti } \\
\cline { 2 - 5 } \cline { 4 - 5 } & $\mathrm{g}$ & $\%$ & $\mathrm{~g}$ & $\%$ \\
\hline Foon (lämmastikväetis) & $28,7 \pm 4,0$ & 100,0 & $25,3 \pm 3,7$ & 100,0 \\
Foon + turbatuhk & $48,9 \pm 9,2$ & 170,4 & $41,8 \pm 7,6$ & 165,2
\end{tabular}

Et vaadeldud katse oli korraldatud võrdlemisi kaaliumirikkal karbonaatse! mullal, on saagi kasvu pōhjustanud mitte turbatuhaga antud kaltsium ega kaalium, vaid teised turbatuhas sisalduvad taimele vajalikud toiteelemendid.

Analoogiline katse tehti ka Märjamaa rajooni «Sirbi ja Vasara» kolhoosi tüüpilisel kamar-karbonaatmullal $\left(\mathrm{pH}_{\mathrm{Kcl}}=6,86\right.$; liikuvat $\mathrm{P}_{2} \mathrm{O}_{5}$ on $2,2 \mathrm{mg}$ ja liikuvat $\mathrm{K}_{2} \mathrm{O}$ on $19,5 \mathrm{mg} 100 \mathrm{~g}$ mulla kohta). Selle katse tulemused on toodud tabelis 5 . Saagina on teraviljade puhul terade kuivaine ja ristiku puhul heina kuivaine esitatud.

Tabel 5

Turbatuha toime karbonaatsel mullal

\begin{tabular}{|c|c|c|c|c|}
\hline \multirow{2}{*}{ Aasta } & \multirow{2}{*}{ Kultuur } & \multirow{2}{*}{ Katsevariant } & \multicolumn{2}{|c|}{ Saak } \\
\hline & & & g & $\%$ \\
\hline $\begin{array}{l}1954 \\
1955\end{array}$ & $\begin{array}{l}\text { Kaer } \\
\text { Ristik } \\
\text { Kaer } \\
\text { Ristik } \\
\text { Hernes } \\
\text { Suvinisu }\end{array}$ & $\begin{array}{l}\text { Foon } \\
\text { Foon + turbatuhk } \\
\text { Foon } \\
\text { Foon + turbatuhk } \\
\text { Foon } \\
\text { Foon + turbatuhk } \\
\text { Foon } \\
\text { Foon + turbatuhk } \\
\text { Foon } \\
\text { Foon + turbatuhk } \\
\text { Foon } \\
\text { Foon + turbatuhk }\end{array}$ & $\begin{array}{r}8,6 \pm 0,4 \\
13,4 \pm 0,6 \\
21,2 \pm 0,5 \\
26,9 \pm 0,7 \\
8,4 \pm 0,2 \\
9,3 \pm 0,1 \\
14,2 \pm 0,1 \\
18,2 \pm 0,0 \\
6,3 \pm 0,2 \\
6,6 \pm 0,1 \\
17,3 \pm 1,6 \\
16,8 \pm 0,9\end{array}$ & $\begin{array}{r}100,0 \\
155,8 \\
100,0 \\
126,8 \\
100,0 \\
110,7 \\
100,0 \\
128,0 \\
100,0 \\
104,8 \\
100,0 \\
97,1\end{array}$ \\
\hline
\end{tabular}


Foto 1. Turbatuhk fosfori asendajana odra puhul:

539 - toitesegu ilma fosforita, 543 - turbatuhk fosfori asemel.
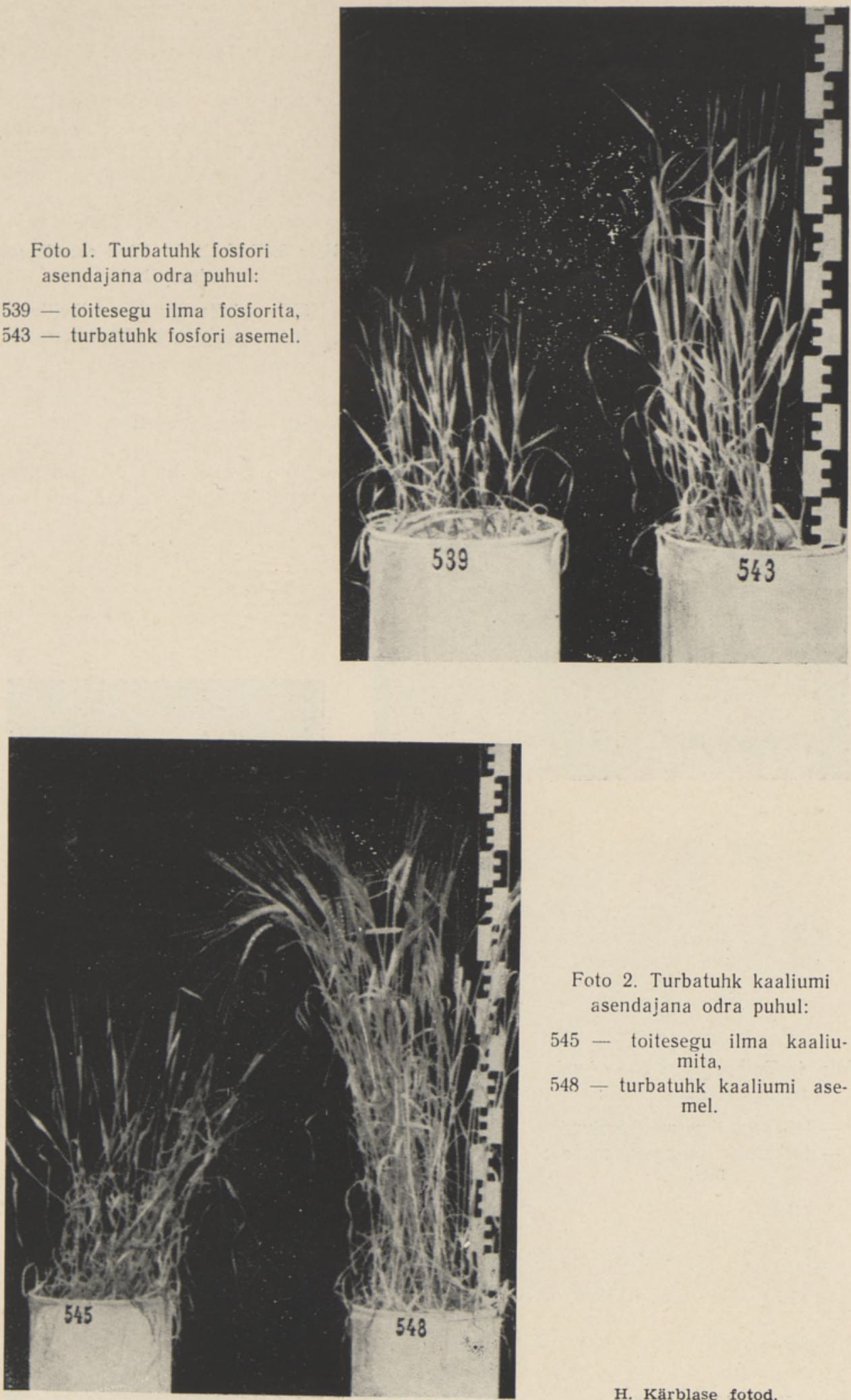

Foto 2. Turbatuhk kaaliumi asendajana odra puhul:

545 - toitesegu ilma kaaliumita,

548 - turbatuhk kaaliumi asemel. 


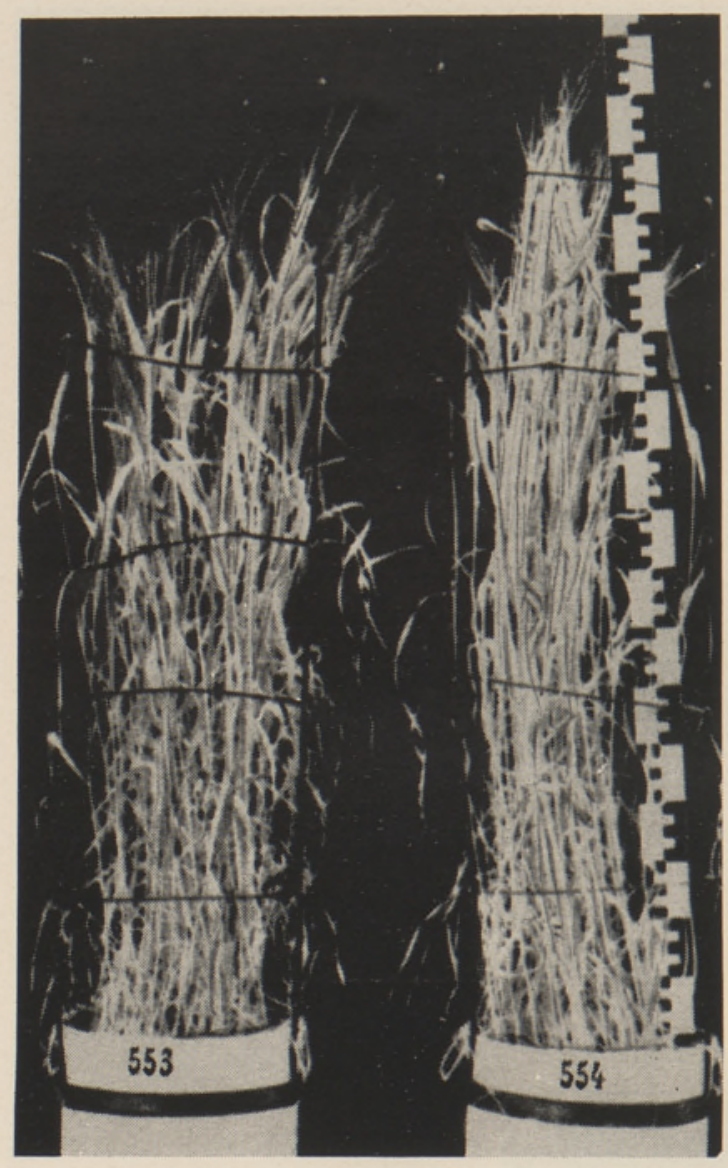

Foto 3. Turbatuhk väävli asendajana odra puhul:

553 - toitesegu ilma väävlita,

554 - turbatuhk väävli asemel.

Foto 4. Turbatuhk magneesiumi asendajana odra puhul:

558 - toitesegu ilma magneesiumita, 561 - turbatuhk magneesiumi asemel.

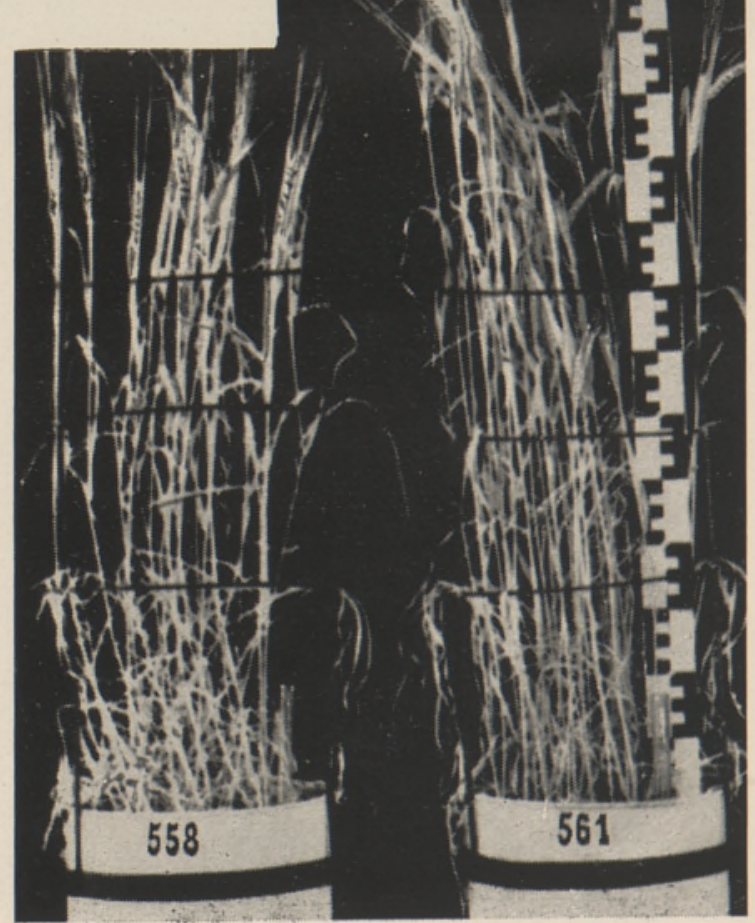


Foto 5 . Turbatuhk väävli asendajana herne puhul:

571 - toitesegu ilma väävlita, 572 - turbatuhk väävli asemel.

H. Kärblase fotod.
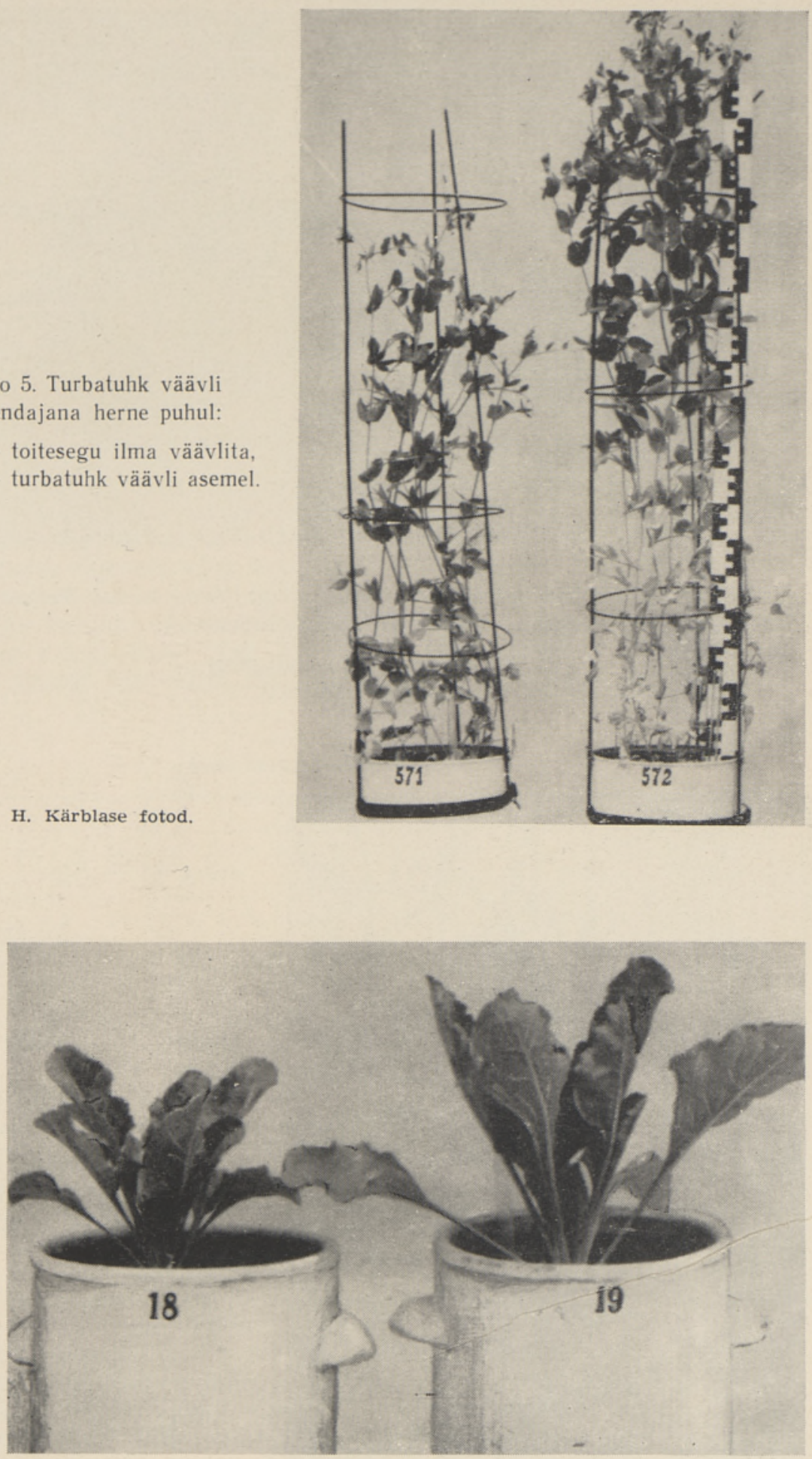

Foto 6. Turbatuha toime karbonaatsel mullal (muld toodud Pärnu-Jaagupi rajooni Kirovi-nimelisest kolhoosist):

$$
\begin{aligned}
& 18 \text { - foon (lämmastikväetis), } \\
& 19 \text { - foon + turbatuhk. }
\end{aligned}
$$




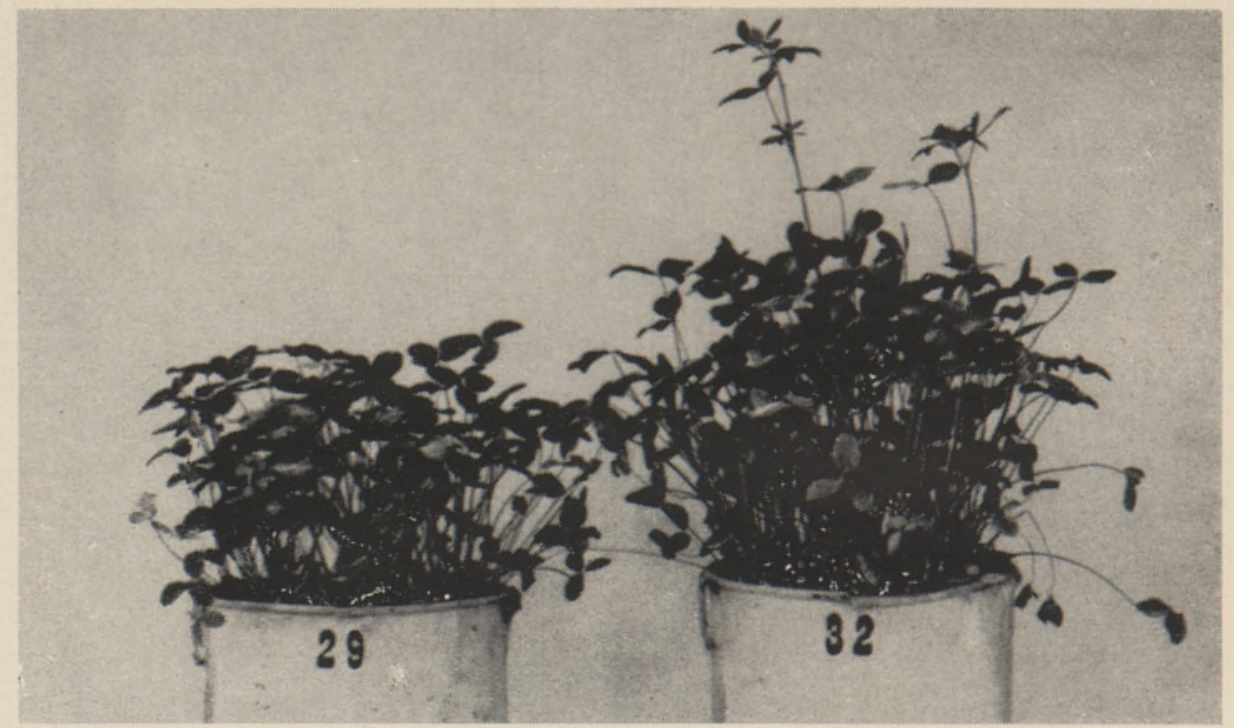

Foto 7. Turbatuha toime karbonaatsel mullal (muld toodud Märjamaa rajooni «Sirbi ja Vasara» kolhoosist):

29 - foon (lämmastikväetis),

32 - foon + turbatuhk.

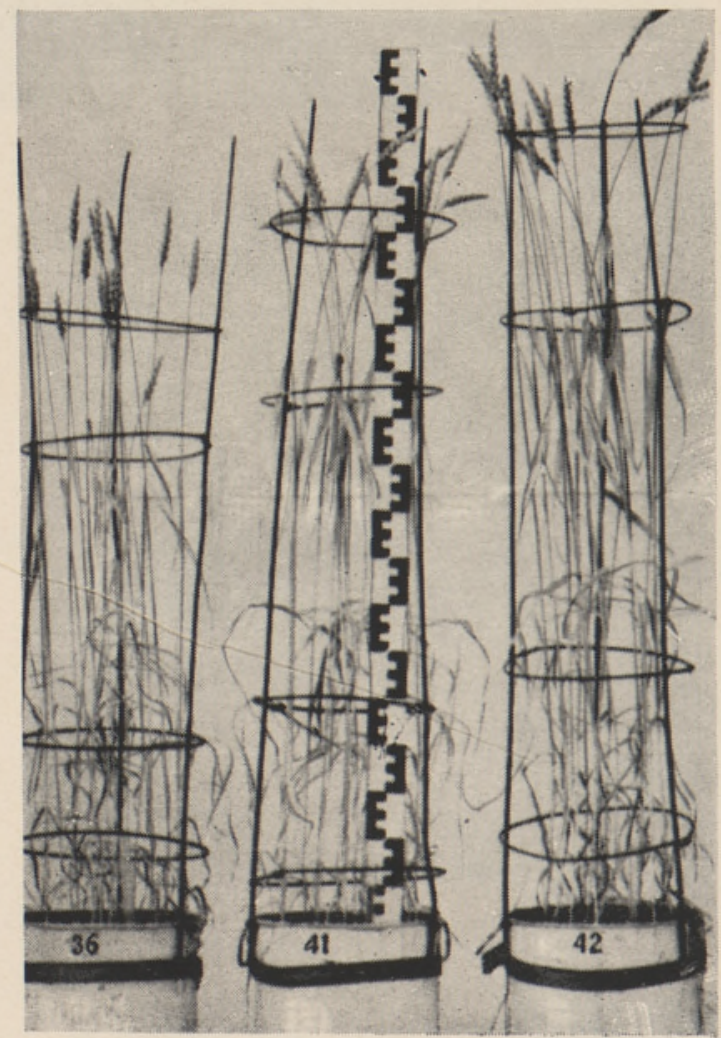

Foto 8 . Turbatuha toime happelisel mullal:

36 - foon (NPK),

41 - foon + nõrglubi,

$42-$ foon + turbatuhk. 
Tabeli 5 andmetest selgub, et turbatuha positiivne toime aastate jook: sul väheneb. Kolm aastat järjest ühel ja samal mullal kestnud katses ilmnes turbatuha positiivne toime kahel esimesel katseaastal, ent kolmandal ta praktiliselt puudus.

Ka Raadi õppe- ja katsemajandis keskmisel liivsavisel leetunud kamar-karbónaatmullal $\left(\mathrm{pH}_{\mathrm{KCl}}=6,77\right.$; liikuvat $\mathrm{P}_{2} \mathrm{O}_{5}$ on $29,6 \mathrm{mg}$ ja liikuvat $\mathrm{K}_{2} \mathrm{O}$ on $10,0 \mathrm{mg} 100 \mathrm{~g}$ mulla kohta) korraldatud pōldkatses saadi turbatuha toimel esimesel katseaastal märksa suurem enamsaak kui teisel.

Nii saadi väetamata lappidelt esimesel katseaastal $9,0 \pm 0,5$ ts $/$ ha $14 \%$ niiskussisaldusega odrateri, turbatuhaga ( $5 \mathrm{t} / \mathrm{ha})$. väetatud lappidelt aga $12,3 \pm 1,0$ ts $/$ ha. Seega kasvas terasaak turbatuha toimel 3,3 ts võrra hektarilt.

Teisel katseaastal saadi väetamata lappidelt kahe lõikuse kogusena $94,1 \pm 1,4$ ts/ha lutserni kuivheina. Turbatuhaga väetatud lappidel oli lutserni kuivheinasaak aga $7,9 \%$ võrra suurem $(101,5 \pm 1,8 \cdot$ ts/ha)

Märksa kestvam on turbatuha väetustoime happelise reaktsiooniga muldadel. Siin on turbatuhk esijoones lubiväetiseks.

Nii oli Tartu rajoonis «Tee Kommunismile» kolhoosi tugevalt leetunud kergel liivsavisel mullal ( $\mathrm{pH} 1 \mathrm{n} \mathrm{KCl}$ leotises $=4,38$ ) korraldatud nõukatses turbatuha toimel saadud enamsaak kolmandal katseaastal peaaegu niisama suur kui esimesel (tab. 6). Kōnesolevas katses on turbatuha kui lubiväetise toimet vōrreldud meil standardse lubiväetise — nõrglubja omaga.

Tabel 6

\section{Lubiväetiste toime võrdlus}

\begin{tabular}{|c|c|c|c|c|c|c|c|c|c|c|c|c|}
\hline \multirow{3}{*}{ Väetis } & \multicolumn{4}{|c|}{1954} & \multicolumn{4}{|c|}{1955} & \multicolumn{4}{|c|}{1956} \\
\hline & \multicolumn{2}{|c|}{$\begin{array}{c}\text { I } \\
\text { Oder }\end{array}$} & \multicolumn{2}{|c|}{$\begin{array}{c}\text { II } \\
\text { Ristik }\end{array}$} & \multicolumn{2}{|c|}{$\stackrel{\text { I }}{\text { Suvinisu }}$} & \multicolumn{2}{|c|}{$\begin{array}{c}\text { II } \\
\text { Ristik }\end{array}$} & \multicolumn{2}{|c|}{$\begin{array}{c}\text { I } \\
\text { Hernes }\end{array}$} & \multicolumn{2}{|c|}{$\begin{array}{c}\text { HI } \\
\text { Kaer: }\end{array}$} \\
\hline & g & $\%$ & $\mathrm{~g}$ & $\%$ & g & $1 \%$ & g & $\%$ & g & $\%$ & g & $\%$ \\
\hline Lubiväetiseta & $\begin{array}{c}34,1 \\
( \pm 0,8)\end{array}$ & 100,0 & $\begin{array}{c}15,0 \\
( \pm 0,5)\end{array}$ & 100,0 & $\begin{array}{c}12,3 \\
( \pm 0,6)\end{array}$ & 100,0 & $\begin{array}{r}27,9 \\
( \pm 0,5)\end{array}$ & 100,0 & $\begin{array}{c}21,9 \\
( \pm 1,5)\end{array}$ & 100,0 & $\begin{array}{c}19,8 \\
( \pm 1,0)\end{array}$ & 100,0 \\
\hline Nõrglubi & $\begin{array}{c}38.1 \\
( \pm 1,0)\end{array}$ & 111,7 & $\begin{array}{r}16,3 \\
( \pm 0,4)\end{array}$ & 108,7 & $\begin{array}{r}14,6 \\
( \pm 03)\end{array}$ & 118,7 & $\begin{array}{r}30,3 \\
( \pm 03)\end{array}$ & 108,6 & $\begin{array}{r}23.6 \\
( \pm 1,3)\end{array}$ & 107,8 & $\begin{array}{r}24,2 \\
( \pm 1,2)\end{array}$ & 122,2 \\
\hline Turbatuhk & $\begin{array}{r}46.3 \\
( \pm 0,5)\end{array}$ & 135,8 & $\begin{array}{r}19.8 \\
( \pm 0,8)\end{array}$ & 132,0 & $\begin{array}{c}17,2 \\
( \pm 0,0)\end{array}$ & 139,8 & $\begin{array}{c}35,1 \\
( \pm 1,1)\end{array}$ & 125.8 & $\begin{array}{c}26,6 \\
( \pm 0,4)\end{array}$ & 121,5 & $\begin{array}{r}28.4 \\
( \pm 1,2)\end{array}$ & 143,4 \\
\hline
\end{tabular}

Lubiväetiste kasutamise positiivset mōju nisutaimede kõrguskasvule teisel katseaastal näitab foto 8 .

Et katse oli korraldatud NPK foonil, siis ei tule turbatuhas sisalduvad kaalium ja fosfor saagi tõstjatena arvesse. Nōrglubjaga väetatud variantides suurenes saak aga vähem kui turbatuhaga väetatud variantides. Viimastes on saaki tõstnud tuhas sisalduvad väävel, magneesium ja mikroelemendid, mis peavad järelikult olema taimede poolt omastatavad.

Turbatuha eelist lubiväetisena ja ta küllaltki püsivat positiivset toimet viljasaagisse tõestavad ka põldkatsete tulemused. Sellekohase näitena esitame tabelis 7 Tartu rajooni «Esimese Mai» kolhoosis saviliivasel keskmiselt leetunud kamar-leetmullal $(\mathrm{pH} 1 \mathrm{n} \mathrm{KCl}$ leotises $==4,67$, hüdrolüütiline happesus $=4,24$ m-ekv. $100 \mathrm{~g}$ mulla kohta) korraldatud kolmeaastase kestusega katsete tulemused.

Lubiväetisena anti tabelis 7 toodud katses à 5 t/ha nõrglupja ja turbatuhka. See annus moodustab turbatuha puhul umbes $1 / 3$ ja nörglubja puhul $3 / 5$ taimede lubjatarbest. Vaatamata sellele, et turbatuhaga anti 
hektarile vähem lupja, saadi tema toimel suurem enamsaak kui nōrglubja toimel.

Turbatuha mõju pōllukultuuride saagisse

\begin{tabular}{|c|c|c|c|c|}
\hline \multirow[b]{2}{*}{ Aasta } & \multirow[b]{2}{*}{ Kultuur } & \multicolumn{3}{|c|}{ Saak ts / ha } \\
\hline & & $\begin{array}{l}\text { Lubiväeti- } \\
\text { seta }\end{array}$ & $\begin{array}{c}\text { Nõrg- } \\
\text { lubjaga }\end{array}$ & $\begin{array}{l}\text { Turba- } \\
\text { tuhaga }\end{array}$ \\
\hline $\begin{array}{l}1955 \\
1956 \\
1957\end{array}$ & $\begin{array}{l}\text { Segavili (teri) } \\
\text { Suvinisu } \\
\text { Segavili (teri) }\end{array}$ & $\begin{array}{r}10,2 \pm 0,1 \\
16,3 \pm 0,2 \\
7,3 \pm 0,1\end{array}$ & $\begin{array}{r}9,9 \pm 0,1 \\
18,2 \pm 0,7 \\
8,1 \pm 0,2\end{array}$ & $\begin{array}{r}11,4 \pm 0,5 \\
20,4 \pm 0,5 \\
8,3 \pm 0,2\end{array}$ \\
\hline
\end{tabular}

Kokkuvōttes võib öelda, et senini väärtusetu ballastina vaadeldud turbatuhk sisaldab rohkesti toiteelemente, mida taimed on vöimelised omastama. Sellest tingituna võib turbatuhka edukalt kasutada väetisena, eriti lubiväetisena.

Eesti Pöllumajanduse Akadeemia

Saabus toimetusse

15. III 1958

\title{
ХИМИЧЕСКИИ СОСТАВ ТОРФЯНОИ ЗОЛЫ И УСВОЯЕМОСТЬ ЕЕ ПИТАТЕЛЬНЫХ ЭЛЕМЕНТОВ РАСТЕНИЯМИ
}

\author{
Х. Кярблане, \\ нандндат сельснохозяйственных наук
}

\section{Резюме}

Ценным местным топливом в Эстонской ССР является торф, при горении которого өстается много золы. Так, при средней зольности торфа в $6 \%$ электростанцин и другие предприятия республики, использующие в качестве топлива торф, должны в год собрать и вывести свыше 33000 т золы.

Образцы торфяной золы, полученные от различных предприятий, содержат $16,10-27,20 \%$ растворимой в соляной кислоте извести, $1,67-3,43 \%$ окиси магния, $1,22-1,89 \%$ окиси калия, $0,97-1,80 \%$ фосфорной кислоты, $1,41-4,15 \%$ серы и, кроме того, еще различные микроэлементы.

Свыше половины калия и почти половина фосфора торфяной золы растворяются в $2 \%$-ной лимонной кислоте.

Результаты вегетационных опытов, заложенных на кварцевом песке и на разных почвах, показали, что содержащиеся в торфяной золе питательные элементы усваиваются растениями.

Торфяная зола является хорошим известковым удобрением, положительный эффект которого превышает эффект известкового туфа и влияние которого не ограничивается одним лишь годом. Она представляет собой хорошее удобренне и на почвах, не нуждающихся в известковании, однако здесь торфяная зола оказывает положительное влияние только на первом и втором году после ее внесения,

Эстонская сельскохозяйственная академия

Поступила в редакцию

15. III 1958 


\section{DIE CHEMISCHE ZUSAMMENSETZUNG DER TORFASCHE UND DIE WURZELLOSLICHKEIT DER DARIN ENTHALTENEN NAHRSTOFFE}

\section{H. Kärblane}

\section{Zusammenfassung}

Die Estnische SSR besitzt im Torf einen wertvollen örtlichen Brennstoff, der bei der Verbrennung leider eine beträchtliche Menge Asche hinterlässt. Bei einem mittleren Aschengehalt des Toríes von $6 \%$, ist für alle Elektrizitätswerke und Betriebe der Republik, wo Torf als Brennmaterial Verwendung findet, mit einer alljährlich abfallenden Aschenmenge von insgesamt über $33000 \mathrm{t} \mathrm{zu}$ rechnen.

Verschiedenen Betrieben entstammende Aschenproben enthielten $16,10-27,20 \%$ in Salzsäure löslichen Ka!k, 1,67-3,43\% Magnesia, 1,22-1,89\% Kali, $0,97-1,80 \%$ Phosphorsäure, $1,41-4,15 \%$ Schwefel und verschiedene Spurenelemente.

Mehr als die Hälite des in der Torfasche enthaltenen $\mathrm{Kalis}\left(\mathrm{K}_{2} \mathrm{O}\right)$ und fast die Hälíte des Phosphors $\left(\mathrm{P}_{2} \mathrm{O}_{5}\right)$ sind in 2-prozentiger Zitronensäure löslich.

Auf Quarzsand und verschiedenen Böden angestellte Geïassversuche haben. ergeben, dass die in der Torfasche enthaltenen Nährstoffe wurzellöslich sind.

Torfasche kann mit Erfolg zur Düngung kalkarmer Böden gebraucht werden, wobei ihre Wirksamkeit die des Kalktufís übertrifft. Als Kalkdünger übt die Torfasche aui die Böden eine nachhaltige Wirkung aus.

Auch für Böden, die keiner Kalkung bedürfen, ist Torfasche ein wirksamer Dünger, nur beschränkt sich ihre positive Wirkung hier lediglich auf ein paar Jahre. 